\title{
Shear viscosity of rhyolite-vapor emulsions at magmatic temperatures by concentric cylinder rheometry
}

\author{
Daniel J. Stein, Frank J. Spera* \\ Institute for Crustal Studies and Department of Geological Sciences, University of California, Santa Barbara, Santa Barbara, \\ CA 93106, USA
}

Received 24 July 2000; received in revised form 18 June 2001; accepted 18 June 2001

\begin{abstract}
The viscosity of natural rhyolitic melt from Lipari, Aeolian Islands and melt-bubble emulsions (30-50 vol\% porosity) generated from Lipari rhyolite have been measured in a concentric cylinder rheometer at temperatures and shear rates in the range $925-1150^{\circ} \mathrm{C}$ and $10^{-3}-10^{-1.2} \mathrm{~s}^{-1}$, respectively, in order to better understand the dependence of emulsion shear viscosity on temperature and shear rate in natural systems. Bubble-free melt exhibits NewtonianArrhenian behavior in the temperature range $950-1150^{\circ} \mathrm{C}$ with an activation energy of $395 \pm 30 \mathrm{~kJ} / \mathrm{mol}$; the shear viscosity is given by $\log \eta_{\mathrm{m}}=-8.320+20624 / T$. Suspensions were prepared from natural rhyolite glass to which small amounts of $\mathrm{Na}_{2} \mathrm{SO}_{4}$ were added as a 'foaming agent'. Reasonably homogeneous magmatic mixtures with an approximate log-normal distribution of bubbles were generated by this technique. Suspension viscosity varied from $10^{6.1}$ to $10^{8.37} \mathrm{~Pa}$ s and systematically correlates with temperature and porosity in the shear stress range $\left(10^{4.26}-10^{5.46}\right.$ $\mathrm{Pa})$ of the experiments. The viscosity of melt-bubble emulsions is described in terms of the relative viscosity, $\eta_{\mathrm{r}}=\eta_{\mathrm{e}} /$ $\eta_{\mathrm{m}}$ where $\eta_{\mathrm{e}}$ is the emulsion viscosity and $\eta_{\mathrm{m}}$ is the viscosity of melt of the same composition and temperature. The dependence of relative viscosity on porosity for magmatic emulsions depends on the magnitude of the capillary number $\mathrm{Ca} \equiv G /\left(\sigma \sigma_{\mathrm{b}}^{-1} \eta_{\mathrm{m}}^{-1}\right)$, the ratio of viscous forces acting to deform bubbles to interfacial forces resisting bubble deformation. For inviscid bubbles in magmatic flows three regimes may be identified. For $\mathrm{Ca}<0.1$, bubbles are nearly spherical and relative viscosity is an increasing function of porosity. For dilute systems, $\eta_{\mathrm{r}}=1+\phi$ given by the classical result of Taylor [Proc. R. Soc. London A 138 (1932) 41-48]. For $\mathrm{Ca}$ in the range $0.1<\mathrm{Ca}<10$, emulsions behave as power law fluids and the relative viscosity depends on shear rate (or Ca) as well as porosity. At high Ca $(\mathrm{Ca}>10)$ an asymptotic regime is reached in which relative viscosity decreases with increasing porosity and is independent of $\mathrm{Ca}$. Our experiments were carried out for $30<\mathrm{Ca}<925$ in order to quantify the maximal effect of bubbles in reducing the viscosity of magmatic emulsions relative to single-phase melt at identical conditions of shear rate and temperature. The viscosity of a $50 \mathrm{vol} \%$ emulsion is a factor of five smaller than that of melt alone. Rheometric measurements obtained in this study are useful in constraining models of magma transport and volcanic eruption mechanics relevant to transport of volatile-saturated magma in the crust and upper mantle. (c) 2002 Elsevier Science B.V. All rights reserved.
\end{abstract}

Keywords: magmatic emulsion; magma rheology; melts and bubbles; relative viscosity

* Corresponding author. Tel.: +1-805-893-3471; Fax: +1-805-893-3471.

E-mail address: spera@magma.geol.ucsb.edu (F.J. Spera). 


\section{Introduction}

It is well known that the solubility of $\mathrm{H}_{2} \mathrm{O}, \mathrm{CO}_{2}$ and other volatile species in magma is pressuredependent and that at low pressure most magma achieves volatile saturation. Some magma becomes volatile-saturated at depths extending well into the lithosphere. For example, kimberlitic magmas owe their rapid (Spera, 1984; Kelley and Wartho, 2000) ascent rates to their low density and viscosity and high compressibility imparted by their significant volatile content. Similarly, the conversion of pressure-volume expansion work into kinetic energy is dramatically apparent during the eruption of $\mathrm{H}_{2} \mathrm{O}$-rich magma from shallow crustal magma bodies characteristic of explosive volcanism. Extreme supersaturation accompanying magma decompression leads to rapid vesiculation and, for volatile volume fraction $(\phi)$ exceeding $\sim 0.5-0.7$, magma fragmentation during ascent and explosive eruption (e.g., Burnard, 1999; Mangan and Sisson, 2000; Martel et al., 2000). Knowledge of the rheological properties of magmatic mixtures - across the range of qualities from a dilute emulsion to large-porosity foams - is essential to better constrain the behavior of magma during decompression, ascent, eruption, and emplacement on Earth and other planetary bodies (e.g., Kieffer et al., 2000).

Despite the common occurrence of volatile-saturated magma, there are surprisingly few laboratory studies of the rheological properties of these emulsions in the range of temperature and shear rate pertinent to magma transport and eruption (Murase, 1962; Stein and Spera, 1992; Bagdassarov and Dingwell, 1992; Lejeune et al., 1999). In this study, we present additional laboratory measurements for the shear viscosity of rhyolite meltvapor emulsions by concentric cylinder rheometry and show that a rhyolite emulsion of porosity $\phi \approx 0.5$ offers a resistance to shear flow more than five times smaller than melt phase alone.

\section{Emulsion rheology and rheodynamic regimes: a brief synopsis}

A critical issue in emulsion rheology is the in- fluence of dynamic state on the shape of vapor bubbles and how, in turn, bubble shape affects the suspension viscosity at fixed porosity and temperature (e.g., see Stein and Spera, 1992). An inconsistency between the exploratory experimental results of Murase (1962) and the analytical results of Taylor (1932) for the dependence of suspension shear viscosity on bubble fraction $(\phi)$ was noted in the geological literature by Shaw (1965) over 35 years ago. By drawing on results from experimental (Bagdassarov and Dingwell, 1992; Stein and Spera, 1992; Lejeune et al., 1999, 2000; Spera and Stein, 2000), simulation (e.g., Loewenberg and Hinch, 1996; Manga et al., 1998; Manga and Loewenberg, 2001) and theoretical studies (Schowalter et al., 1968; Frankel and Acrivos, 1970) a consistent picture can be constructed. This picture enables one to estimate the relative shear viscosity of dilute and concentrated magmatic emulsions across the range of shear rates pertinent to natural systems. A synopsis of this view is presented to put our experimental measurements in context.

In crystal-melt mixtures, the dispersed phase acts as a 'hard' (non-deformable) inclusion and the viscosity of the suspension strictly increases as the solid fraction increases. Many parametric expressions relating the shear viscosity to the volume fraction of hard spheres have been proposed (Shaw, 1969; Ryerson et al., 1988; Lejeune and Richet, 1995). One such scheme for computing the suspension viscosity as a function of crystal fraction useful for petrological calculations is given in Spera (2000). For a low-viscosity inclusion (e.g., a bubble) the issue is more complex. At very low shear rate (quantified explicitly below), bubbles behave as non-deformable inclusions and consequently, the relative viscosity $\left(\eta_{\mathrm{r}} \equiv \eta_{\mathrm{e}} / \eta_{\mathrm{m}}\right)$ of the suspension, defined as the ratio of emulsion viscosity $\left(\eta_{\mathrm{e}}\right)$ to melt viscosity $\left(\eta_{\mathrm{m}}\right)$, increases as the volume fraction of bubbles $(\phi)$ increases. Taylor (1932) derived an expression for the viscosity of a dilute suspension of inviscid inclusions: $\eta_{\mathrm{r}}=1+\phi$. At higher bubble fractions, the empirical expression $\eta_{\mathrm{r}}=\left[1-K_{\mathrm{o}} \phi\right]^{-5 / 2}$ with $K_{\mathrm{o}} \approx 3 / 2$ is found to approximate the relative viscosity of mixed polymer emulsions (viscous bubbles) reasonably well (Pal and Rhodes, 1989). There are many such empirical formulations especially in the chemical 
engineering literature far too voluminous to cite here. It is important to note that these expressions are valid in the limit of small Reynolds number based on the typical bubble radius $\left(\operatorname{Re}_{\mathrm{b}} \equiv \rho_{\mathrm{e}} G r_{\mathrm{b}}^{2} /\right.$ $\left.\eta_{\mathrm{m}}\right)$ and at shear rates where bubble shapes depart little from sphericity. The bubble Reynolds number is defined in terms of the density of the emulsion $\left(\rho_{\mathrm{e}}\right)$, the shear rate $(G)$ and the characteristic bubble radius $\left(r_{\mathrm{b}}\right)$. The departure of a bubble from sphericity depends on the capillary number, $\mathrm{Ca} \equiv \eta_{\mathrm{m}} G r_{\mathrm{b}} / \sigma$ where $\sigma$ represents the interfacial tension between vapor and melt. The capillary number is the ratio between viscous forces acting to distort a bubble from sphericity relative to the melt/vapor interfacial tension which acts to maintain bubble sphericity. The capillary number can be viewed as a dimensionless shear rate by writing $\mathrm{Ca}=G /\left(\sigma r_{\mathrm{b}}^{-1} \eta_{\mathrm{m}}^{-1}\right)$. The numerator represents the shear rate within the emulsion for a particular flow defined by external conditions independent of the material whereas the denominator represents the scale shear rate found by balancing viscous and interfacial forces along a bubble wall. Small values of $\mathrm{Ca}$ correspond to conditions with dominant interfacial tension and spherical or nearly spherical bubbles. This is favored in a finely dispersed, low-melt-viscosity emulsion subject to small rates of deformation such as in volatile-saturated stagnant magma. In a flow with significant momentum transport, bubbles respond to viscous traction by acquiring shapes that depend on the balance between viscous and interfacial forces. Discussion of the effects of viscosity ratio $\left(\lambda \equiv \eta_{\mathrm{v}} / \eta_{\mathrm{m}}\right)$ between a bubble and its surrounding fluid as well as capillary number may be found in the literature (e.g., Grace, 1982; Stein and Spera, 1992; Kennedy and Pozrikidis, 1994; Manga et al., 1998). In bubbly magmatic flows, $\lambda$ is essentially zero and hence bubble shape depends solely on the magnitude of $\mathrm{Ca}$.

Although the bubble Reynolds number is virtually always $\ll 1$ (negligible microscale inertia) in magmatic flows, in natural systems capillary numbers span the range $10^{-2}-10^{3}$ (Stein and Spera, 1992; Manga et al., 1998; Spera and Stein, 2000). Three distinct dynamic regimes for bubbly flows ( $\phi<0.5$, approximately) are found based on the magnitude of the capillary number. In the
low-Ca regime $(\mathrm{Ca}<0.1)$, bubbles are deformed only slightly from sphericity. The maximum bubble elongation, defined $E=l / b$ varies with $\mathrm{Ca}$ according to $E=\{(1+\mathrm{Ca}) /(1-\mathrm{Ca})\}^{2 / 3}$ where $l$ and $b$ represent the semi-major and semi-minor axes of the deformed prolate spheroid bubble of volume $(4 / 3) \pi l b^{2}$. For example, at $\mathrm{Ca}=0.1$ (the limit of the small $\mathrm{Ca}$ regime) $l / b \approx 1.15$. In this regime, the Taylor expression for dilute emulsions holds for the dependence of relative viscosity on bubble volume fraction and the suspension viscosity is greater than that of the melt phase alone. These low-Ca flows behave as Newtonian fluids with a linear dependence of shear stress on shear rate. For capillary number $0.1<\mathrm{Ca}<10$ one anticipates a transitional regime in which the relative viscosity depends not only on bubble fraction $(\phi)$ but also on the shear rate $(G)$. The shear rate dependence manifests itself as a $\mathrm{Ca}$ number dependence of the relative viscosity. This can be understood by noting that the capillary number is essentially a dimensionless shear rate. Scaling results developed by Reinelt and Kraynik (1989) and Kraynik (1988) suggest $\eta_{\mathrm{r}} \sim \mathrm{Ca}^{-1 / 3}$ in the transitional regime at least for concentrated emulsions. For more dilute emulsions, the power law exponent may be closer to unity. Finally, in the high-Ca regime, bubbles attain highly elongate shapes that align with the flow (Hinch and Acrivos, 1980). In the high-Ca regime, $\eta_{\mathrm{r}}$ at fixed $\phi$ becomes asymptotic to some high shear rate limiting viscosity and is independent of $\mathrm{Ca}$. At large $\mathrm{Ca}$, instabilities associated with bubble break-up and other unsteady effects such as bubble-tipstreaming become important and complicate the picture beyond the simple steady-state view. One needs to consider these regimes in detail in order to understand the shear viscosity of magmatic bubble-melt mixtures.

In this study, we report the results of experimental rheometry of rhyolite melt-vapor emulsions at high temperatures and varying bubble content under Couette flow (simple shear) conditions in the high-Ca number regime. The melt utilized in the experiments is devolatilized rhyolite obsidian from the Aeolian island of Lipari, (Table 1a) with laboratory-produced bubble contents between 30 and $50 \mathrm{vol} \%$. We also describe tech- 
niques developed to generate stable, relatively homogeneous melt-vapor emulsions with approximate log-normal bubble size distributions suitable for rheometric study. By combining our experimental data with existing high-temperature data, theory, numerical simulations and studies of analog (low-temperature) emulsions a first-order picture of the steady-state rheological properties of magmatic emulsions across the range of relevant capillary numbers can be presented.

\section{Experimental procedures}

The experiments focus on the variation of emulsion relative viscosity with temperature, bubble volume fraction and shear rate in the high-Ca regime. The high-temperature Couette rotational rheometer used in these experiments is described in detail in Stein and Spera (1998). Relatively small uncertainties are introduced by measurement of emulsion temperature, rotation rate and torque (related to shear stress in the fluid). Temperature is measured $\pm 2 \mathrm{~K}$ using a Pt-Rh thermocouple located within the inner cylinder (torque tube), no more than several millimeters from the sample itself. Sample container (outer cylinder) rotation rates can be controlled to within several parts per thousand, and torque can typically be measured to better than $2 \%$. In high-temperature cylindrical rheometry, the immersion length of the inner cylinder is known less precisely than other parameters and is uncertain by approximately $10 \%$. These uncertainties were established during calibration runs using NBS silicate viscosity standards. NBS quotes an uncertainty of \pm 0.029 units in $\log \eta$ for NBS-717. We are able to recover the NBS values within $\pm 0.020 \log \eta$ units for temperatures in the range $650-1000^{\circ} \mathrm{C}$ and shear rates corresponding to those used in the experiments.

A challenge in this work is the preparation of stable, homogeneous and isotropic emulsions on the scale of the sample volume of $\sim 40 \mathrm{~cm}^{3}$. We have developed two methods for preparing silicate emulsions suitable for rheometric study by conducting a series of about 25 experiments using a variety of starting materials and heating schedules closely simulating the time-temperature history of a typical rheometric experiment.

In the first set of emulsion-preparation experiments, chemically unmodified powdered samples of the Lipari rhyolite were used. Starting materials were prepared by grinding the natural glass and separating the serial grain sizes by sieving. This natural rhyolite glass contains approximately $0.44 \mathrm{wt} \% \mathrm{H}_{2} \mathrm{O}$ and is essentially aphyric. The success of the procedure for making stable emulsions relies on the fact that some temperature-timeparticle-size combination exists such that during the course of an experiment, water will diffuse out of a particle slowly compared to the rate of viscous relaxation of grain boundaries of the (randomly packed) glass particles. When enough time has elapsed to allow grain boundary annealing to occur, water that subsequently diffuses out of a glass particle remains trapped within the bulk sample and a stable emulsion is created. The porosity of the resultant emulsion depends on the precise details of the particle-size $-T-t$ trajectory as well as melt composition.

The kinetics of the emulsion-forming process can be appreciated by a simple scale analysis. The diffusive loss of water from a glass particle occurs on a time scale $t \approx x^{2} / D$ where $x$ is the particle size and $D$ is the diffusivity of water in the supercooled melt or glass. At $1100^{\circ} \mathrm{C}$, the diffusivity of water in rhyolite melt is $\sim 2.5 \times 10^{-10}$ $\mathrm{m}^{2} / \mathrm{s}$ (Shaw, 1974; Watson and Baker, 1991; Watson, 1994; Chakraborty, 1995). The characteristic time for glass particle dewatering is roughly $1 \mathrm{~h}$ for a mm-sized particle. The thermal response time of the sample, a function of furnace and sample size (about $50 \mathrm{~cm}^{3}$ ) and heat transport within the furnace-sample assembly, is also about $1 \mathrm{~h}$. In the range $1000-1150^{\circ} \mathrm{C}$, water diffusion is fast enough in Lipari rhyolite so that $\mathrm{H}_{2} \mathrm{O}$ can escape from grains less than $\sim 0.25 \mathrm{~mm}$ in diameter and hence from the porous powder bulk sample because gravity-driven viscous relaxation (grain sintering) takes longer than grain dewatering. In this case, an emulsion cannot be prepared. In contrast, for glass particles greater than $\sim 1$ $\mathrm{mm}$, viscous relaxation of powders takes place and the permeability of the powder decreases on a time scale faster than loss of water from the 
grain. Therefore, vapor becomes trapped and a fairly uniform dispersion of bubbles develops and remains stable over the course of a rheometric experiment. By dropping the temperature to $\sim 1000^{\circ} \mathrm{C}$ the emulsion is stable for days to weeks or longer. By conducting a series of experiments with Lipari rhyolite glass with varying target temperature, heating time and particle grain size, we have been able to synthesize emulsions and foams with porosity in the range $0.2<\phi<0.7$. The relationship between the variables controlling the emulsion-generating process needs to be worked out for a given bulk composition of melt since the initial water content, diffusivity of $\mathrm{H}_{2} \mathrm{O}$ and viscosity-temperature relationship vary with composition.

A second method for preparation of a stable and homogeneous emulsion was also developed. In this method the starting material is powdered (sub-mm particles) rhyolite glass. To this powder small amounts $(0.1-1.0 \mathrm{wt} \%)$ of the foaming agent $\mathrm{Na}_{2} \mathrm{SO}_{4}$ are added. The function of this agent is to react with the silicate glass and generate $\mathrm{SO}_{2}$ gas (Zarzycki, 1991, p. 434). This process, used for the removal of tiny, unwanted bubbles in industrial glass production, relies on the fact that gases are more soluble in $\mathrm{SO}_{2}$ than in melt. A melt can be 'scrubbed' of unwanted gas by coalescence and rapid rise of large $\mathrm{SO}_{2}$ bubbles to the surface of the melt. We have been able to exploit the incipient stage of the fining process by: (1) controlling the amount of fining gas by varying glass $/ \mathrm{NaSO}_{4}$ ratio; (2) maintaining temperature low enough to preclude coalescence and Stokes ascent of the bubbles; and (3) controlling the temperature-time history of the sample in the temperature range where the reaction between sulfate and silicate melt is rapid and $\mathrm{SO}_{2}$ gas is liberated. Emulsions in the range $0.25<\phi<0.55$ are produced using this method.

The rheological experiments described below were performed using $\mathrm{Na}_{2} \mathrm{SO}_{4}$ as a fining agent. The post-experiment compositions of rhyolite starting material and a post-experimental composition following addition of $1 \mathrm{wt} \% \mathrm{Na}_{2} \mathrm{SO}_{4}$ are presented in Table 1a,b, along with the composition of natural Lipari rhyolite glass. The addition of small amounts of fining agent did not alter the shear viscosity of bubble-free melt within the limits of experimental uncertainty of $\sim 0.03$ in $\log \eta$ units.

Samples of powdered rhyolite containing $0-1$ wt $\%$ of $\mathrm{Na}_{2} \mathrm{SO}_{4}$ were packed into the annulus of the rheometer. The end gap, or space between the bottom of the inner cylinder and the bottom of the sample within the outer cylinder or cup, was approximately $1 \mathrm{~cm}$; immersion depths of $4-6 \mathrm{~cm}$ were used in the experiments and measured before and after the experiment. The samples containing $1 \mathrm{wt} \% \mathrm{Na}_{2} \mathrm{SO}_{4}$ expanded by about $40-50 \%$ during heating, resulting in somewhat greater immersion lengths, and on some occasions sample was extruded above the top of the sample assembly due to volumetric expansion accompanying gas evolution. This occurrence made the post-experiment evaluation of immersion length sometimes difficult, as it produced shear conditions not strictly characteristic of Couette flow in at least some portion of the sample.

The heating rate was approximately $10-20 \% \mathrm{~min}$ above $800^{\circ} \mathrm{C}$, and somewhat less below that temperature in order to minimize thermal stresses in the ceramic rheometer components. Furnace controller set point was raised to $1225^{\circ} \mathrm{C}$ until the indicated sample temperature approached $1200^{\circ} \mathrm{C}$ at which point the furnace temperature was rapidly reduced by switching furnace power off. After power cutoff, sample temperature tended to increase slightly, reaching 1200 $1210^{\circ} \mathrm{C}$, and then decreased until the sample equilibrated with a new furnace set-point in the range $950-1150^{\circ} \mathrm{C}$. Rheometric measurements were begun once thermal equilibrium was attained. The duration of heating above $1150^{\circ} \mathrm{C}$ was approximately 15-30 min. Most of the specimens prepared in this manner achieved a porosity $40-50 \mathrm{vol} \%$. One sample, containing $0.5 \mathrm{wt} \%$ of $\mathrm{Na}_{2} \mathrm{SO}_{4}$, was cyclically heated to $1200^{\circ} \mathrm{C}$ and cooled several times, and its final measured porosity was $\sim 30 \mathrm{vol} \%$.

Rheometric measurements were conducted isothermally at angular velocity $(\Omega)$ ranging from 0.0005 to $0.2 \mathrm{radian} / \mathrm{s}$ depending on sample temperature which was in the range $925-1150^{\circ} \mathrm{C}$. Torque signal was sampled at a rate of $20 \mathrm{~s}^{-1}$ for periods up to $2 \mathrm{~min}$; measurements with a torque 
Table 1a

Composition of Lipari rhyolite

\begin{tabular}{lccc}
\hline & Liparite & Liparite $^{\mathrm{a}}$ & Liparite $^{\mathrm{a}, \mathrm{b}}$ \\
\hline $\mathrm{SiO}_{2}$ & 73.99 & 74.70 & 74.40 \\
$\mathrm{Al}_{2} \mathrm{O}_{3}$ & 13.20 & 13.28 & 13.22 \\
$\mathrm{TiO}_{2}$ & 0.077 & 0.08 & 0.08 \\
$\mathrm{FeO}^{\mathrm{c}}$ & 1.64 & 1.65 & 1.64 \\
$\mathrm{MnO}$ & 0.064 & & \\
$\mathrm{CaO}$ & 0.76 & 0.77 & 0.77 \\
$\mathrm{MgO}$ & 0.00 & 0.0 & 0.00 \\
$\mathrm{~K}_{2} \mathrm{O}$ & 5.18 & 5.22 & 5.2 \\
$\mathrm{Na}$ & 4.27 & 4.3 & 4.74 \\
$\mathrm{P}_{2} \mathrm{O}$ & & & \\
$\mathrm{Total}$ & 0.020 & 100.0 & 100.35 \\
$\mathrm{LOI}(\%)$ & 99.20 & & \\
\hline
\end{tabular}

a Composition measured after completion of experiment.

b Composition after addition of $1.0 \mathrm{wt} \% \mathrm{Na}_{2} \mathrm{SO}_{4}$.

c Total iron as FeO.

signal-to-noise below 10 were discarded. Duplicate measurements were conducted at each temperature and shear rate. Shear stresses from $10^{4.2}$ to $10^{5.6} \mathrm{~Pa}$ were generated, and viscosity ranged from $10^{5.9}$ to $10^{8.6} \mathrm{~Pa}$ s. Porosity was determined after each experiment from immersion densitometry of glass chips recovered from the sample assembly, weighed in air and ethanol using a Jolly balance. In addition, several thin sections were prepared with epoxy resin impregnation of the pores for the purposes of acquiring and studying images of sample textures to assess total porosity and bubble size distributions. The results of the image analysis are reported in a subsequent section. Porosity determined from the images was consistent with those obtained by densitometry within a few percent relative. For the purposes of establishing relative viscosity, rheometric measurements were also conducted on a bubble-free sample of unmodified Lipari rhyolite and another

Table $1 \mathrm{~b}$

Listing of samples and $\mathrm{Na}_{2} \mathrm{SO}_{4}$ contents

\begin{tabular}{lll}
\hline Experiment & Type & $\mathrm{Na}_{2} \mathrm{SO}_{4}$ content $(\mathrm{wt} \%)$ \\
\hline $\mathrm{M} 981023$ & Melt & 0.0 \\
$\mathrm{M} 990506$ & Melt & 1.0 \\
E980924 & Emulsion & 1.0 \\
E980926 & Emulsion & 1.0 \\
E981009 & Emulsion & 0.5 \\
E990212 & Emulsion & 1.0 \\
\hline
\end{tabular}

to which $1.0 \mathrm{wt}^{\%} \mathrm{Na}_{2} \mathrm{SO}_{4}$ had been added, with subsequent degassing at a temperature of $1500^{\circ} \mathrm{C}$ to insure completion of the fining reaction and eliminate porosity by 'draining' of the emulsion. Bulk compositions for the samples are given in Table 1a,b.

\section{Porosity and bubble size distributions}

Following completion of rheometric experiments, specimens are allowed to cool slowly to room conditions inside the furnace. Once the sample temperature falls below $T_{\mathrm{g}}(\sim 1100 \mathrm{~K})$ textural and viscous relaxation cease, and characteristics of the bubble size and shape distribution at the close of the experiment are preserved. Measurements were conducted so that textures were generally characteristic of the highest capillary number conditions achieved during the experiment.

The experimental charge, a cylindrical plug of length $\sim 6 \mathrm{~cm}$ and diameter $\sim 3 \mathrm{~cm}$, is diamondsawed into several radial slabs. Due to thermal stresses, this procedure cannot always be completed successfully; fracturing of the sample assembly sometimes occurs due to remnant thermal stress. Once removed, the sample is examined for bubble homogeneity. If the sample is heterogeneous, the rheometric data are rejected and no further analysis is performed. We have found sample heterogeneity to be a problem about half of the time. If the sample is homogeneous, a number of $\sim 1-3-\mathrm{g}$ pieces are collected and an estimate of sample bulk porosity is made by immersion densitometry. We have found that for homogeneous-appearing samples (hand lens or binocular examination), porosity measured on the Jolly balance is reproducible (on separate chips from the same sample) to within several percent relative when care is taken to minimize experimental error.

The radial slabs are then prepared for microscopy and subsequent image analysis including impregnation by blue epoxy as a pore identification aid. We obtain measures of the total area of the (2-D) image and determine frequencies of the major and minor axes of 2-D bubbles. These data are then analyzed with additional stereological and 

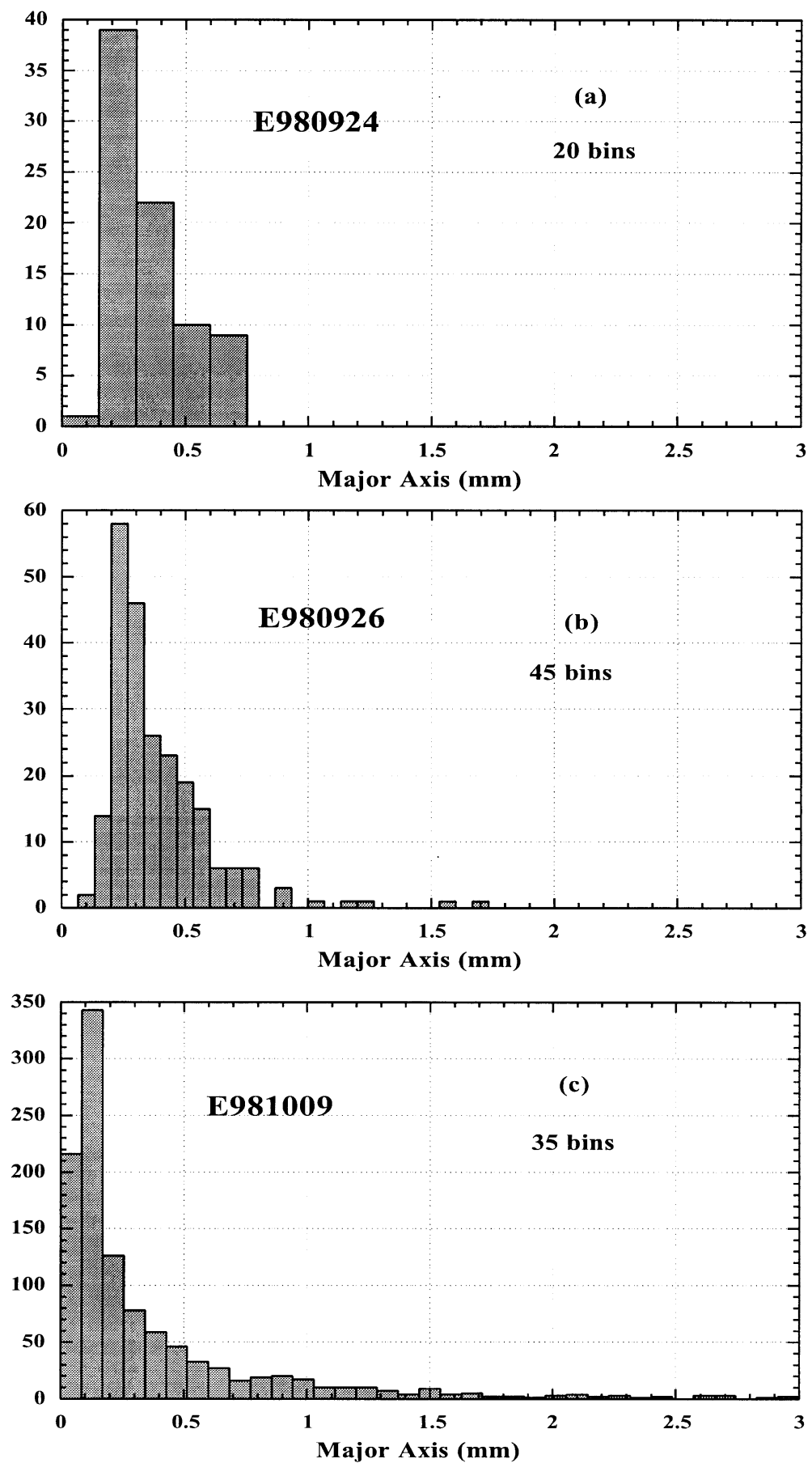

Fig. 1. (a-c) Bubble size frequency $(N)$ distributions for rheometric samples E980924, E980926 and E981009. Major axes of bubbles measured in cross-section using circumscribed ellipse to represent bubbles. Major axes are approximately log-normally distributed. See Table 2 for details of sample statistics. All bubble distributions are unimodal. 
Table 2

Bubble size distribution statistics

\begin{tabular}{|c|c|c|c|}
\hline & E980924 & E980926 & E981009 \\
\hline Porosity $(\phi)$ & 0.55 & 0.48 & 0.29 \\
\hline \multicolumn{4}{|l|}{ Major axis (mm) } \\
\hline Mean & 0.35 & 0.39 & 0.39 \\
\hline S.D. & 0.15 & 0.22 & 0.56 \\
\hline Maximum & 0.69 & 1.71 & 5.32 \\
\hline \multicolumn{4}{|l|}{ Minor axis (mm) } \\
\hline Mean & 0.17 & 0.18 & 0.11 \\
\hline S.D. & 0.06 & 0.08 & 0.21 \\
\hline Maximum & 0.34 & 0.67 & 3.08 \\
\hline \multicolumn{4}{|l|}{ Bubble elongation $(l / b)$} \\
\hline Mean & 2.04 & 2.25 & 1.90 \\
\hline S.D. & 0.72 & 0.82 & 0.63 \\
\hline Maximum & 5.14 & 7.33 & 7.18 \\
\hline $\begin{array}{l}\text { Mean radius }(\mathrm{mm}) \\
{\left[r_{\mathrm{b}}=(\mathrm{lb})^{1 / 2}\right]}\end{array}$ & 0.244 & 0.265 & 0.207 \\
\hline
\end{tabular}

statistical software to obtain quantitative information regarding the bubble size distribution and total porosity. Different sections from the same rheological specimen, when available, are used to address sample homogeneity and data quality issues.

The results from image analysis used to obtain porosity and bubble size distribution information are presented in Fig. 1a-c and Table 2. Bubble size major axis distribution histograms for samples E980924, E980926, and E981009 of porosity $0.55,0.48$ and 0.29 , respectively, are shown in Fig. 1. Bubbles produced by the fining method are unimodal and approximately log-normally distributed with rather large standard deviations. A 'typical' bubble radius is $0.2 \mathrm{~mm}$. Sample E981009 exhibits the largest mean bubble elongation (3.54) and bubble size range. This sample was subject to the largest shear rate of any experiment $G \approx 0.067 \mathrm{~s}^{-1}$ which corresponds to $\mathrm{Ca} \approx 250$. The relatively large elongation of bubbles observed in this sample is consistent with the high capillary numbers of the experiments. Fig. 2 is a photomicrograph of a representative sample (post-run) texture from E980926 $(\phi=0.48)$ which shows the effects of high $\mathrm{Ca}(\sim 203-406)$ on bubble shape. Elongations in the range $2-8$ are observed with the larger values for the large-volume bubbles.

\section{Rheometric results}

Rheometric data indicating post-experiment porosity, shear stress, temperature, shear rate, and viscosity for all experiments are summarized in Table 3a,b. Shear stress, shear rate and Newtonian viscosity for Liparite melt (single phase) at $950-1125^{\circ} \mathrm{C}$ data are presented in Table $3 \mathrm{a}$. Melt viscosity as a function of temperature is given by the Arrhenian expression: $\ln \eta_{\mathrm{m}}=$ $-19.1573+394820 / R T$ and is independent of shear rate. Viscosity data for bubble-free melt from two

Table 3a

Rheometric data - melts

\begin{tabular}{llll}
\hline$T$ & $\begin{array}{l}\text { Log } \tau \\
(\mathrm{Pa})\end{array}$ & $\begin{array}{l}\text { Log } \gamma \\
\left(\mathrm{s}^{-1}\right)\end{array}$ & $\begin{array}{l}\text { Log } \eta \\
(\mathrm{Pa} \mathrm{s})\end{array}$ \\
\hline M981023 & & & \\
1000 & 5.287 & -2.563 & 7.85 \\
1000 & 5.257 & -2.563 & 7.82 \\
1000 & 5.487 & -2.383 & 7.87 \\
1050 & 5.397 & -1.863 & 7.26 \\
1100 & 5.127 & -1.663 & 6.79 \\
1100 & 5.107 & -1.663 & 6.77 \\
1150 & 4.687 & -1.563 & 6.25 \\
M990506 & & & \\
950 & 5.587 & -3.013 & 8.6 \\
950 & 5.587 & -3.013 & 8.6 \\
1000 & 5.607 & -2.263 & 7.87 \\
1000 & 5.607 & -2.263 & 7.87 \\
1000 & 5.617 & -2.263 & 7.88 \\
1000 & 5.507 & -2.383 & 7.89 \\
1000 & 5.497 & -2.383 & 7.88 \\
1000 & 5.507 & -2.383 & 7.89 \\
1050 & 5.407 & -1.863 & 7.27 \\
1050 & 5.407 & -1.863 & 7.27 \\
1050 & 5.397 & -1.863 & 7.26 \\
1050 & 5.567 & -1.683 & 7.25 \\
1050 & 5.567 & -1.683 & 7.25 \\
1050 & 5.157 & -2.083 & 7.24 \\
1050 & 5.157 & -2.083 & 7.24 \\
1100 & 5.127 & -1.563 & 6.69 \\
1100 & 5.107 & -1.563 & 6.67 \\
1100 & 5.067 & -1.563 & 6.63 \\
1100 & 5.387 & -1.263 & 6.65 \\
1100 & 5.397 & -1.263 & 6.66 \\
1100 & 5.417 & -1.263 & 6.68 \\
1125 & 4.907 & -1.563 & 6.47 \\
1125 & 4.897 & -1.563 & 6.46 \\
1125 & 5.267 & -1.163 & 6.43 \\
1125 & 5.247 & -1.163 & 6.41 \\
\hline \multicolumn{1}{c}{ a Containing } & minor $(<2 \%$ & by volume) & of residual air \\
bubbles. & & & \\
& & &
\end{tabular}




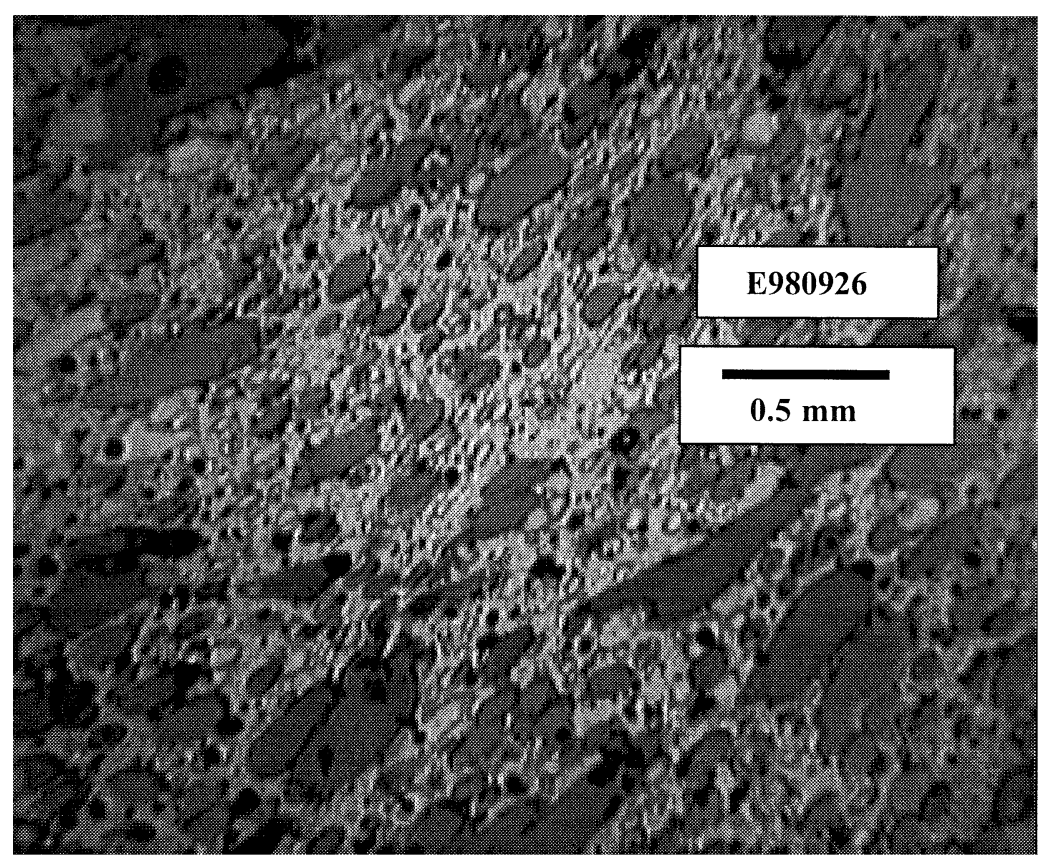

Fig. 2. Photomicrograph of E990926, showing typical features of size and elongation $(E=l / b)$ characteristics of bubbles. Length scale indicated by bar. Uniform bubble shape distribution is consistent with a relatively homogeneous distribution of shear throughout the sample during Couette flow. Although homogeneous on the scale of several $\mathrm{mm}$, the bubble number density is heterogeneous at the sub-mm scale. Variations in bubble number density in a single sample may be related to the range of measured relative viscosities depicted in Fig. 5.

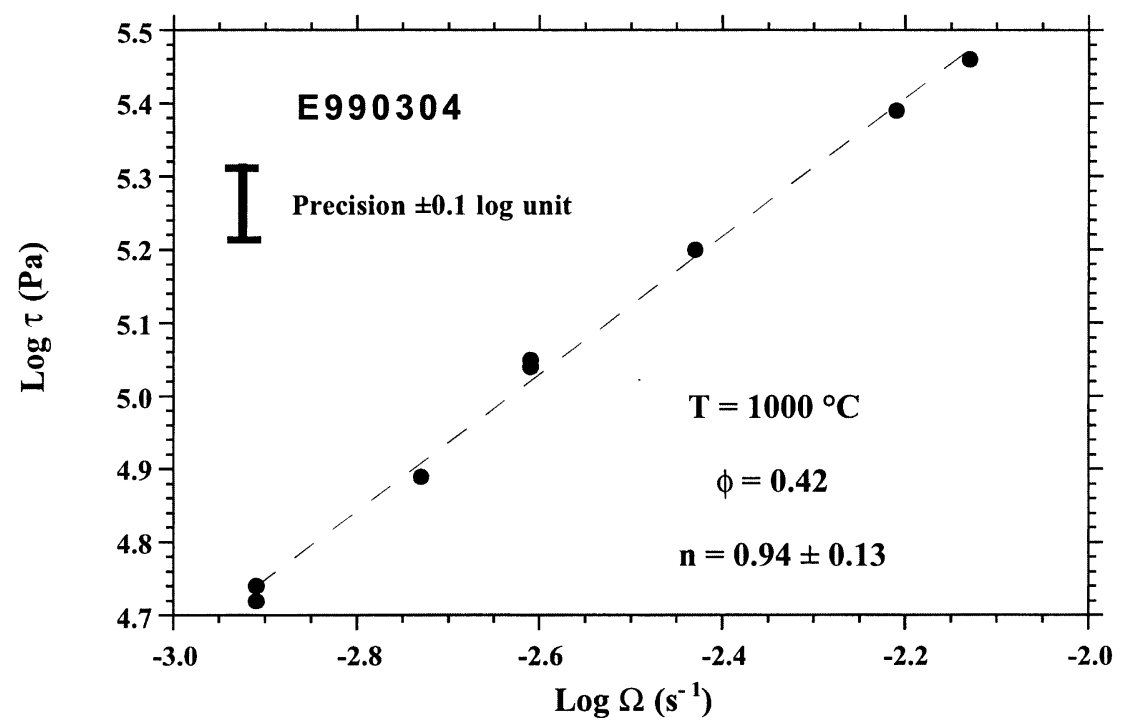

Fig. 3. Power law analysis for E990304 at $1000^{\circ} \mathrm{C}$. Estimated precision of shear stress measurement is \pm 0.1 in units of $\log \tau$. Power law index $(n)$ from regression of log shear stress vs. log angular velocity is $0.94 \pm 0.13$, indicating Newtonian model is justified within the precision of the data set. The power law constitutive relation is: $\tau=m G^{n}$ where $G$ is the shear rate and $n$ is the power law index. 
Table 3b

Rheometric data - emulsions

\begin{tabular}{|c|c|c|c|c|c|}
\hline $\begin{array}{l}T \\
\left({ }^{\circ} \mathrm{C}\right) \\
\end{array}$ & $\begin{array}{l}\log \tau \\
(\mathrm{Pa})\end{array}$ & $\begin{array}{l}\log \gamma \\
\left(\mathrm{s}^{-1}\right)\end{array}$ & $\begin{array}{l}\log \eta \\
(\mathrm{Pa} \mathrm{s})\end{array}$ & $\mathrm{Ca}^{\mathrm{a}}$ & $\eta_{\mathrm{r}}$ \\
\hline E980924 & $\phi=0.55$ & & & & \\
\hline 1000 & 4.637 & -2.563 & 7.2 & 187 & 0.21 \\
\hline E980926 & $\phi=0.48$ & & & & \\
\hline 1000 & 4.837 & -2.563 & 7.4 & 203 & 0.33 \\
\hline 1000 & 5.087 & -2.263 & 7.35 & 406 & 0.29 \\
\hline E981009 & $\phi=0.29$ & & & & \\
\hline 1000 & 4.887 & -2.563 & 7.45 & 159 & 0.37 \\
\hline 1000 & 5.397 & -2.263 & 7.66 & 317 & 0.6 \\
\hline 1000 & 4.747 & -2.863 & 7.61 & 80 & 0.54 \\
\hline 1000 & 5.067 & -2.563 & 7.63 & 159 & 0.56 \\
\hline 1000 & 5.317 & -2.263 & 7.58 & 317 & 0.5 \\
\hline 1100 & 5.277 & -1.183 & 6.46 & 252 & 0.58 \\
\hline 1100 & 4.527 & -1.963 & 6.49 & 42 & 0.62 \\
\hline 1100 & 4.457 & -2.083 & 6.54 & 32 & 0.69 \\
\hline E990212 & $\phi=0.45$ & & & & \\
\hline 925 & 5.217 & -2.963 & 8.18 & 625 & 0.19 \\
\hline 925 & 5.207 & -2.963 & 8.17 & 625 & 0.19 \\
\hline 925 & 5.217 & -2.963 & 8.18 & 625 & 0.19 \\
\hline 950 & 5.227 & -2.563 & 7.79 & 698 & 0.18 \\
\hline 950 & 5.257 & -2.563 & 7.82 & 698 & 0.19 \\
\hline 975 & 5.277 & -2.263 & 7.54 & 640 & 0.22 \\
\hline 975 & 5.017 & -2.563 & 7.58 & 321 & 0.24 \\
\hline 1000 & 5.137 & -2.083 & 7.22 & 459 & 0.22 \\
\hline 1000 & 4.917 & -2.263 & 7.18 & 303 & 0.2 \\
\hline 1000 & 4.927 & -2.263 & 7.19 & 303 & 0.2 \\
\hline 1025 & 4.837 & -2.083 & 6.92 & 224 & 0.23 \\
\hline 1025 & 4.867 & -2.083 & 6.95 & 224 & 0.24 \\
\hline 1050 & 4.567 & -2.083 & 6.65 & 112 & 0.24 \\
\hline 1050 & 4.607 & -2.083 & 6.69 & 112 & 0.26 \\
\hline 1075 & 4.747 & -1.713 & 6.46 & 135 & 0.3 \\
\hline 1075 & 5.007 & -1.383 & 6.39 & 289 & 0.26 \\
\hline 1100 & 4.227 & -1.863 & 6.09 & 50 & 0.25 \\
\hline 1100 & 4.537 & -1.563 & 6.1 & 100 & 0.25 \\
\hline 1100 & 4.257 & -1.863 & 6.12 & 50 & 0.26 \\
\hline 1125 & 4.607 & -1.263 & 5.87 & 108 & 0.27 \\
\hline E990304 & $\phi=0.42^{\mathrm{b}}$ & & & & \\
\hline 925 & 5.407 & -2.963 & 8.37 & 630 & 0.30 \\
\hline 1050 & 4.947 & -1.863 & 6.81 & 188 & 0.35 \\
\hline 1000 & 4.717 & -2.563 & 7.28 & 153 & 0.25 \\
\hline 1000 & 4.737 & -2.563 & 7.30 & 153 & 0.26 \\
\hline 1000 & 5.037 & -2.263 & 7.31 & 306 & 0.27 \\
\hline 1000 & 5.047 & -2.363 & 7.31 & 243 & 0.27 \\
\hline 1000 & 5.197 & -2.093 & 7.29 & 453 & 0.26 \\
\hline 1000 & 5.387 & -1.863 & 7.25 & 769 & 0.24 \\
\hline 1000 & 5.457 & -1.783 & 7.24 & 924 & 0.23 \\
\hline 1000 & 4.887 & -2.383 & 7.27 & 232 & 0.25 \\
\hline 1100 & 4.987 & -1.263 & 6.25 & 202 & 0.36 \\
\hline 1100 & 4.687 & -1.563 & 6.25 & 101 & 0.36 \\
\hline
\end{tabular}

a Porosity of E990304 as estimated by bulk densitometry only.

b Capillary number based on mean bubble radius computed as geometric mean of minor axis and major axis dimensions determined in image analysis (see Table 2). 

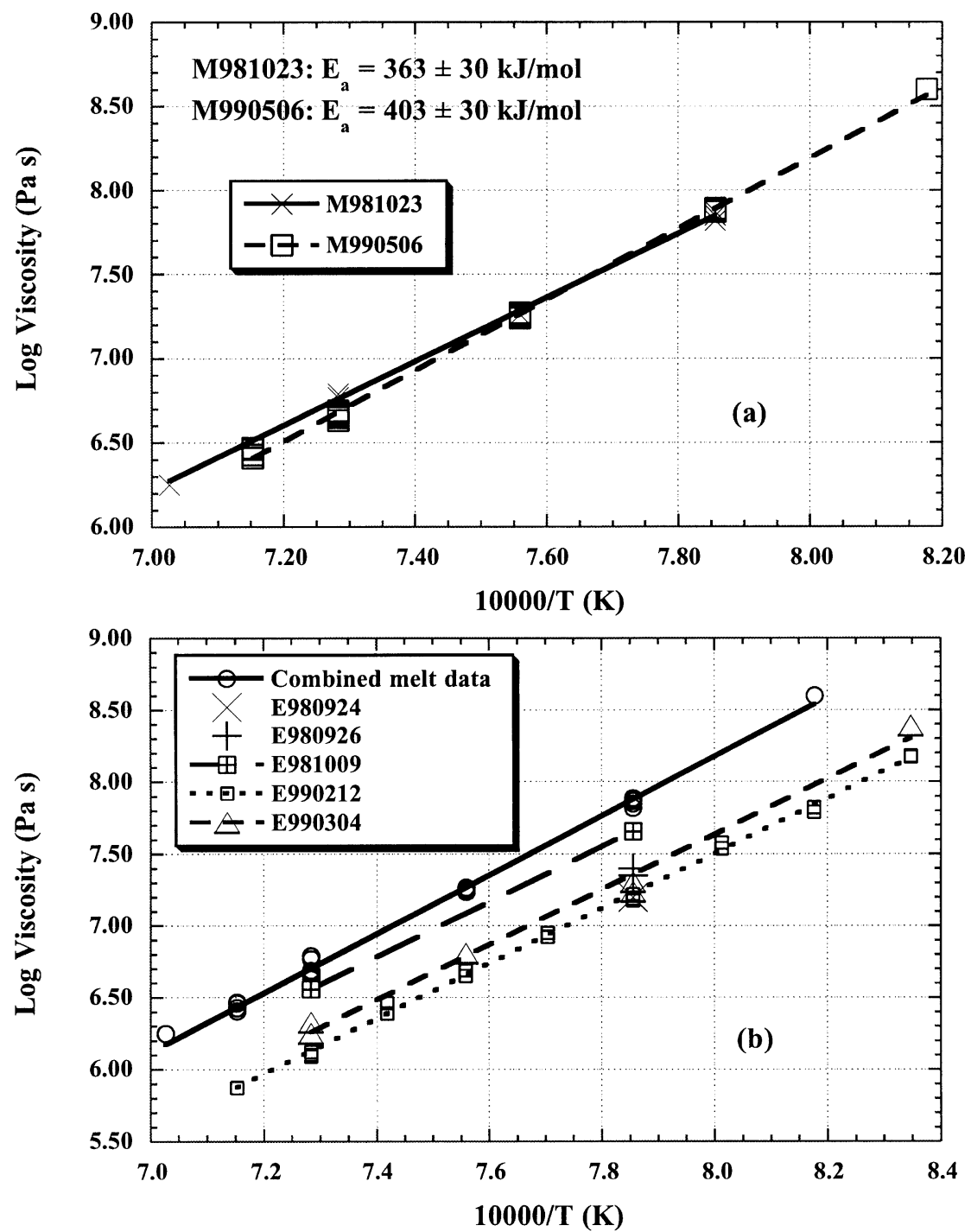

Fig. 4. (a) Viscosity-temperature relations for Liparite melt. M981023 (solid curve) is Liparite melt without addition of $\mathrm{Na}_{2} \mathrm{SO}_{4}$. M990506 (dashed curve) is Liparite melt after addition of $1 \mathrm{wt} \% \mathrm{Na}_{2} \mathrm{SO}_{4}$ and high-temperature reaction. (b) Viscosity-temperature data for Liparite emulsions, with combined results from melt measurements (solid curve) shown for reference. Results for E980924 and E980926 are single data points at $1000^{\circ} \mathrm{C}$. Results for polythermal data (E981009, E990212, E990304) are shown with fits to Arrhenian model regressions. Calculated activation energies for the emulsions are identical (within error) to the combined melt data. Relative viscosity decreases regularly with increasing bubble content, but does not vary with temperature within the precision of the data.

experiments (M981023 and M990506) are plotted in Fig. 4a. The data for M990506 show that addition of minor amounts of $\mathrm{Na}_{2} \mathrm{SO}_{4}$ affects neither the viscosity nor the activation energy within experimental error. In the temperature range of the experiments Lipari rhyolite melt conforms to Newtonian-Arrhenian behavior quite closely.

Results for emulsions are provided in Table $3 b$ where values of the capillary number and relative viscosity for each emulsion are given along with 
shear stress, shear rate and emulsion viscosity. $\mathrm{Ca}$ was calculated using a constant value for the interfacial energy $\sigma=0.27 \mathrm{~N} / \mathrm{m}$ (Walker and Mullins, 1981; Kucuk et al., 1999). The fundamental experimental quantities are ordered pairs of torque along the inner cylinder (torque tube) and angular velocity of the outer cylinder (cup) at fixed $\phi$ and constant temperature. Primary values were transformed to shear stress and shear rate using established procedures (Spera et al., 1988; Stein and Spera, 1992, 1993, 1998). On a plot of the logarithm of the shear stress versus the logarithm of angular velocity, the slope gives the power law exponent $n$ in the constitutive relation $\tau=m G^{n}$. A representative plot is given in Fig. 3 for $\mathrm{E} 990304(\phi \approx 0.42)$ at $1000^{\circ} \mathrm{C}$. With a conservative estimate of error of 0.1 in $\log \tau$ units, the power law index $(n)$ of this emulsion is, within the limits of uncertainty, equal to unity. This emulsion therefore behaves as a Newtonian fluid with a linear shear stress-shear rate relation. Similar plots for the other emulsions along other isotherms show no apparent correlation of the power law index with porosity or temperature. Power law exponents are not substantially different from unity for any emulsion. Emulsions studied here behave, therefore, as Newtonian mixtures in the range of shear rate, temperature and porosity examined. Note that capillary numbers lie in the range 34-1040. We conclude that in the high-Ca number regime of the experiments, relative viscosity is essentially independent of capillary number (shear rate).

The emulsion Newtonian viscosity was calculated from the Margules equation applicable concentric cylinder geometry of the instrument: $\eta_{\mathrm{e}}=M\left(1 / R_{\mathrm{i}}^{2}-1 / R_{\mathrm{o}}^{2}\right) / 4 \pi \Omega h$ and results are collected in Table 3b. $M$ is the measured torque, $\Omega$ is the angular velocity of the rotating cup, $h$ is the immersion length of the inner rheometer cylinder, $R_{\mathrm{i}}$ is the inner cylinder radius $(0.476 \mathrm{~cm})$ and $R_{\mathrm{o}}$ is the outer cylinder radius $(1.508 \mathrm{~cm})$. The uncertainty for melt viscosity and emulsion viscosity is estimated to be 0.05 and $0.1 \log$ units, respectively. The larger uncertainty for the emulsions reflects the greater uncertainty in $h( \pm 15 \%)$. No systematic hysteresis or thixotropic behavior was observed during the measurements. Total shear strain for individual experiments at fixed shear stress ranged from 100 to $1000 \%$. This is an important advantage of concentric cylinder rheometry over viscosity derived from viscometric flows using the Gent-type rheometer (Gent, 1960). For example, in the experiments of Lejeune et al. (1999) using the Gent-type apparatus typical strain values are in the range 5-30\%. Likewise, in the study of Bagdassarov and Dingwell (1992) total strain was reported as several percent. From the simulations presented in Manga and Loewenberg (2001) it is noted that for $\mathrm{Ca}$ in the transitional regime, transient rheological effects (thixotropy) are present until total strain exceeds $100 \%$. Although large enough strains were probably achieved in our experiments to reach quasi-steady state, this may not have been the case in previous studies.

Viscosity-temperature data for samples E981009, E990212 and E990304 are summarized in Fig. $4 \mathrm{~b}$ along with combined data for all bubble-free experiments. The most extensive polythermal data are for E990212 $(\phi \approx 0.45)$. Viscosity data for samples E980924 $(\phi=0.55)$ and E980926 $(\phi=0.48)$ were obtained only at $1000^{\circ} \mathrm{C}$ and are included in the figure for comparison. Similar to bubble-free melt, emulsions display Arrhenian behavior with viscous activation energy of about $375 \pm 30 \mathrm{~kJ} / \mathrm{mol}$, characteristic of a high-SiO ${ }_{2}$ rhyolitic melt. From the similarity of slopes in Fig. 4, it is evident that porosity does not exert an important quantitative effect on activation energy for viscous flow in these experiments.

\section{Relative viscosity: variation with porosity}

Relative viscosity of all emulsions was computed from melt viscosity measured at the same temperature as the emulsion; in some cases a small interpolation of the melt viscosity using the Arrhenian relation was required. Relative viscosity results for each emulsion viscosity measurement are included in Tables $3 \mathrm{a}$ and $3 \mathrm{~b}$. Fig. 5 summarizes experimental relative viscosity variation with porosity and includes results from other workers (Lejeune et al., 1999; Bagdassarov and 
Dingwell, 1992; Sura and Panda, 1990; Ducamp and Raj, 1989; Rahaman et al., 1987) and some theoretical bounds. The results from the present study and those of Lejeune et al. (1999) are presented as bands indicating a range of relative viscosity obtained over a range of temperatures for each viscometric sample. Although Lejeune et al. (1999) assert that the relative viscosity shows a systematic variation with temperature, our results provide no supporting evidence. In this study the variation of relative viscosity at fixed porosity is due to inter-sample variability associated with: (1) the heterogeneous distribution of bubbles; (2) the presence of a range of bubble sizes; and (3) experimental uncertainty of cylinder immersion depth $(h)$. All three effects probably contribute to the uncertainty.

In the ranges of shear stress $\left(1.7 \times 10^{4}-3.0 \times 10^{5}\right.$ $\mathrm{Pa})$, shear rate $\left(0.0011-0.066 \mathrm{~s}^{-1}\right)$, capillary number (30-925), porosity $(0.29-0.55)$ and temperature $\left(925-1125^{\circ} \mathrm{C}\right)$ covered in the experiments, emulsions are less viscous than bubble-free melt of the same composition. Emulsion viscosity monotonically decreases as porosity increases in the range $29-55 \%$ porosity. For a concentrated emulsion $(\phi \approx 0.5)$ in the high-Ca regime, the viscosity is smaller by a factor of five compared to bubblefree melt. That is, the emulsion is five times less viscous than melt alone at the same temperature. The emulsion viscosity ranges between $10^{8.37}$ and $10^{5.87} \mathrm{~Pa} \mathrm{~s}$ over the temperature range of the experiments.

\section{Discussion}

All of the emulsions from the present study exhibit a relative viscosity less than unity, with a systematic decrease in relative viscosity with increasing porosity. Description of this phenomenon using both analytical (Manga et al., 1998) and empirical (Bagdassarov and Dingwell, 1992) approaches has been attempted. The short-long dashed curve (diamond symbol) in Fig. 5 represents the relation $\eta_{\mathrm{r}}=1-\phi$, given by Manga et al. (1998) as valid in the limit $\mathrm{Ca} \rightarrow \infty$ and assumes that bubbles do not affect the flow. This expression is equivalent to the Voight bound which as- sumes that strain is uniform in the mixture. The thin continuous curve is the Hashin-Shtrikman upper bound in the limit $\mathrm{Ca} \rightarrow \infty$ of $\eta_{\mathrm{r}}=1-(5 \phi)$ $(3+2 \phi))$. The lower dashed curve in Fig. 5 is taken from a least-squares regression by Bagdassarov and Dingwell (1992) of their experimental data, fit to the form $\eta_{\mathrm{r}}=1 /(1+a \phi)$, with $a=22.4$. The results of Lejeune et al. (1999) at low porosity showing $\eta_{\mathrm{r}}>1$ may be an indication that transient rheological effects associated with small total strain were important in their experiments (see also Spera and Stein, 2000; Lejeune et al., 2000 for discussion). Lejeune et al. (1999) did not explicitly compute capillary numbers of their experiments. Based on information gleaned from their study, however, it appears that their experiments were mainly in the high-Ca regime where one expects $\eta_{\mathrm{r}}$ to be a monotonically decreasing function of porosity. For $\phi>0.30$ our results compare well with those of Lejeune et al. (1999).

Simulations of bubble deformation in simple shear flow fields have been undertaken by several investigators (Zhou and Pozrikidis, 1993; Kennedy and Pozrikidis, 1994; Charles and Pozrikidis, 1998). Recent simulations by Manga and Loewenberg (2001) relevant to inviscid bubbles $(\lambda \rightarrow 0)$ in the limit $\mathrm{Ca} \rightarrow \infty$ are included in Fig. 5. Their numerical results are consistent with extrapolation of our experimental results for $\phi \leq 0.40$, the maximum value of the porosity considered in the simulations. The shear strains developed in the simulations are small compared to the total shear strains developed experimentally. This may explain the small difference between extrapolation of numerical results and the measurements at $\phi>0.4$ in Fig. 5.

The rheological measurements of this study are applicable to near-surface magmatic flows such as the growth of viscous lava domes and rhyolitic lava flows and the ascent of magma in volcanic conduits. As an illustration, consider flow of homogeneous bubbly rhyolitic magma in a parallelwalled 'crack' of width $2 B$ and length $W$ at $T=950^{\circ} \mathrm{C}$. Magma is driven upwards by the pressure difference associated with its buoyancy relative to surrounding country rock. The volumetric discharge for a Newtonian fluid in this simple flow is $Q=2 / 3 \Delta \rho g B^{3} W / \eta_{\mathrm{r}} \eta_{\mathrm{m}}$ and the mean shear 


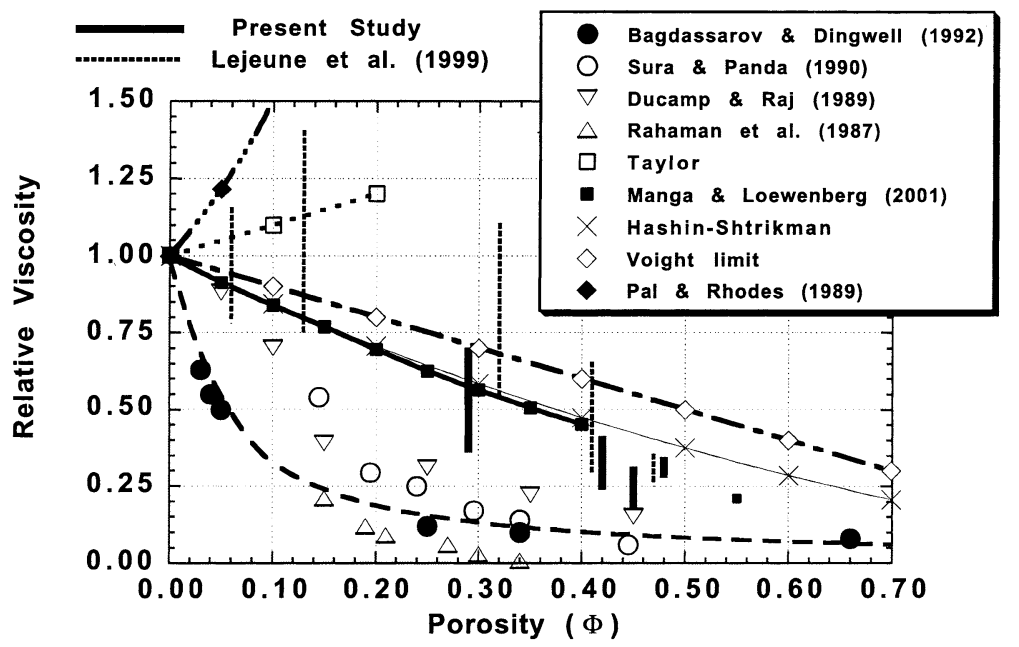

Fig. 5. Relative viscosity variation with porosity for rheometric measurements on emulsions and porous melts. Volume fraction porosity indicated on horizontal axis. Results from present study are indicated by solid bar at each respective bubble volume fraction. Results of Lejeune et al. (1999) are indicated by vertical dashed bars. Filled circles are data of Bagdassarov and Dingwell (1992). Lower dashed curve is an empirical fit to Bagdassarov and Dingwell data to the form $\eta_{\mathrm{r}}=1 /(1+22.4 \phi)$. Open circles, open triangles and inverted open triangles are for powder systems from Sura and Panda (1990), Rahaman et al. (1987) and Ducamp and Raj (1989), respectively. The analytical result of Taylor (1932) for non-deformable inclusions in a dilute emulsion as well as the Hashin-Shtrikman and Voight limits are shown as well. The relative viscosity for concentrated suspensions of viscous drops from Pal and Rhodes (1989) is also shown for comparison. Heavy continuous curve is glazed eye-ball fit to numerical simulation results (solid squares) of Manga and Loewenberg (2001).

rate for magma in the crack is $G \approx \Delta \rho g B / 2 \eta_{\mathrm{r}} \eta_{\mathrm{m}}$ where $\Delta \rho$ is the density difference between magma and country rock. For a typical bubble radius $r_{\mathrm{b}}=0.2 \mathrm{~mm}$, vapor-melt interfacial tension of $0.27 \mathrm{~N} / \mathrm{m}, \phi=0.4$, dike width of $10 \mathrm{~m}, \Delta \rho=1500$ $\mathrm{kg} / \mathrm{m}^{3}$, crack length $W=100 \mathrm{~m}, \eta_{\mathrm{r}}=0.25$ and $\eta_{\mathrm{m}}=7.6 \times 10^{7} \mathrm{~Pa} \mathrm{~s}, \mathrm{Ca}=110$ and the high-Ca regime is clearly indicated. In this example, the volumetric discharge is $Q \approx 20 \mathrm{~m}^{3} / \mathrm{s}$, the mass discharge $\approx 1.6 \times 10^{4} \mathrm{~kg} / \mathrm{s}$ and the mean shear rate is $5.7 \times 10^{-3} \mathrm{~s}^{-1}$. In this case, the bubbly rhyolite magma discharges at a rate more than four times larger than bubble-free magma due to its lower viscosity and density.

\section{Concluding remarks}

Vapor bubbles are invariably present and play an important role in the movement of magma, yet study of the rheological properties of magmatic emulsions has barely commenced. The dependence of relative shear viscosity of an emulsion depends upon the dimensionless shear rate known as the capillary number. In natural magmatic flows $10^{-2}<\mathrm{Ca}<10^{3}$ and three regimes can be identified. High capillary numbers tend to prevail in intermediate- and high-silica systems given typical flow conditions and bubble sizes. In the highCa limit, emulsion viscosity can be almost an order of magnitude lower than that of melt alone at the same temperature. In addition to the effect of bubbles on the shear viscosity of magmatic mixtures, the presence of bubbles imparts an elasticity which is manifested in non-zero normal material stress material functions $\left(\tau_{11}-\tau_{33}, \tau_{22}-\tau_{33}\right)$ of the magmatic mixture. In a Newtonian fluid, normal stress differences are identically zero. Non-zero normal stresses will markedly affect the morphology and growth dynamics of lava flows and endogenous domes. Indeed, in experimental concentric cylinder viscometry the importance of normal stress differences can be readily observed by the phenomenon of rob climb, a hallmark of fluids with non-zero normal stress components. Experimental study of normal stress coefficients in bub- 
bly magmatic flows and low-temperature analog fluid mixtures is needed to quantitatively evaluate normal stress effects in magmatic mixtures. The most important point and one worth emphasizing is that bubbles can either increase or decrease the viscosity of magma relative to that of the melt depending on the dynamic conditions of the flow. The banding in 'flow-banded' rhyolite is defined by parallel regions (bands) of higher and lower porosity, respectively. In the high-Ca limit, the more porous bands will be regions of significantly lower viscosity than the more massive regions and this will have an important effect on the morphology and dynamics of the flow.

\section{Acknowledgements}

Support from the US Department of Energy (BES-Geosciences) and the National Science Foundation is gratefully acknowledged. The efforts of Nick Woodward (DOE) and Sonia Esperança (NSF) were especially helpful to the completion of the experimental work. The review by M. Manga (Berkeley), discussion with Alison Rust (Oregon State) and comments from an anonymous reviewer greatly improved the manuscript.

\section{References}

Bagdassarov, N.Sh., Dingwell, D.B., 1992. A rheological investigation of vesicular rhyolite. J. Volcanol. Geotherm. Res. 50, 307-322.

Burnard, P., 1999. Eruption dynamics of 'popping rock' from vesicle morphologies. J. Volcanol. Geotherm. Res. 92, 247258.

Chakraborty, S., 1995. Diffusion in silicate melts. In: Stebbins, J.F., McMillan, P.F., Dingwell, D.B. (Eds.), Structure, Dynamics, and Properties of Silicate Melts. Rev. Mineral. 32, pp. 411-503.

Charles, R., Pozrikidis, C., 1998. Significance of the dispersedphase viscosity on the simple shear flow of suspensions of two-dimensional liquid drops. J. Fluid Mech. 365, 205-234.

Ducamp, V.C., Raj, R., 1989. Shear and densification of glass powder compact. J. Am. Ceram. Soc. 72, 798-804.

Frankel, N.A., Acrivos, A., 1970. The constitutive equation for a dilute emulsion. J. Fluid Mech. 44, 65-78.

Gent, A.N., 1960. Theory of the parallel plate viscometer. Br. J. Appl. Phys. 11, 85-87.
Grace, H.P., 1982. Dispersion phenomena in high viscosity immiscible fluid systems and application of static mixers as dispersion devices in such systems. Chem. Eng. Commun. 14, 225-277.

Hinch, E.J., Acrivos, A., 1980. Long slender drops in a simple shear flow. J. Fluid Mech. 98, 305-328.

Kelley, S.P., Wartho, J.A., 2000. Rapid kimberlite ascent and the significance of Ar-Ar ages in xenolith phlogopites. Science 289, 609-611.

Kennedy, M.R., Pozrikidis, C., 1994. Motion and deformation of liquid drops and the rheology of dilute emulsions in simple shear flow. Computers Fluids 23, 251-278.

Kraynik, A.M., 1988. Foam flows. Annu. Rev. Fluid Mech. 20, 325-357.

Kieffer, S.W., Lopes-Gautier, R., McEwen, A., Smythe, W., Keszthelyi, L., Carlson, R., 2000. Prometheus: Io's wandering plume. Science 288, 1204-1208.

Kucuk, A., Clare, A.G., Jones, L., 1999. An estimation of the surface tension for silicate glass melts at $1400^{\circ} \mathrm{C}$ using statistical analysis. Glass Technol. 40, 149-153.

Lejeune, A.-M., Richet, P., 1995. Rheology of crystal-bearing silicate melts An experimental study at high viscosities. J. Geophys. Res. 100, 4215-4229.

Lejeune, A.-M., Bottinga, Y., Trull, T., Richet, P., 1999. Rheology of bubble-bearing magmas. Earth Planet. Sci. Lett. 166, 71-84.

Lejeune, A.M., Bottinga, Y., Trull, T.W., Richet, P., 2000. Rheology of bubble-bearing magmas reply to a critical comment by Spera and Stein. Earth Planet. Sci. Lett. 175, 333334.

Loewenberg, M., Hinch, E.J., 1996. Numerical simulation of a concentrated emulsion in shear flow. J. Fluid Mech. 321, 395-419.

Manga, M., Castro, J., Cashman, K.V., Loewenberg, M., 1998. Rheology of bubble-bearing magmas. J. Volcanol. Geotherm. Res. 87, 15-28.

Manga, M., Loewenberg, M., 2001. Viscosity of magmas containing highly deformable bubbles. J. Volcanol. Geotherm. Res. 105, 19-24.

Mangan, M., Sisson, T., 2000. Delayed, disequilibrium degassing in rhyolite magma: decompression experiments and implications for explosive volcanism. Earth Planet. Sci. Lett. 183, 441-455.

Martel, C., Bourdier, J.L., Pichavant, M., 2000. Textures, water content and degassing of silicic andesites from recent plinian and dome-forming eruptions at Mount Pelee volcano (Martinique, Lesser Antilles arc). J. Volcanol. Geotherm. Res. 96, 191-206.

Murase, T., 1962. Viscosity and related properties of volcanic rocks. J. Fac. Sci. Hokkaido Univ. Japan Ser. VII 1, $487-$ 584

Pal, R., Rhodes, E., 1989. Viscosity concentration relationships for emulsions. J. Rheol. 33, 1021-1045.

Rahaman, M.N., DeJonghe, L., Scherer, G., Brook, R., 1987. Creep and densification during sintering of powder compact. J. Am. Ceram. Soc. 70, 766-774.

Reinelt, D.A., Kraynik, A.M., 1989. Viscous effects in the 
rheology of foams and concentrated emulsions. J. Colloid Interphase Sci. 132, 491-503.

Ryerson, F.J., Weed, H.C., Piwinskii, A.J., 1988. Rheology of subliquidus magmas, I. Picritic compositions. J. Geophys. Res. 93, 3421-3436.

Schowalter, W.R., Chaffey, C.E., Brenner, H., 1968. Rheological behavior of a dilute emulsion. J. Colloid Interface Sci. 26,152 .

Shaw, H.R., 1974. Diffusion of $\mathrm{H}_{2} \mathrm{O}$ in granitic liquids: Part I. Experimental data; Part II. Mass transfer in magma chambers. In: Geochemical Transport and Kinetics. Carnegie Inst. Washington Publ. 634, 139-170.

Shaw, H.R., 1965. Comments on viscosity, crystal settling, and convection in granitic systems. Am. J. Sci. 272, 120-152.

Shaw, H.R., 1969. Rheology of basalt in the melting range. J. Petrol. 10, 510-535.

Spera, F.J., 1984. Carbon dioxide in petrogenesis: III. Role of volatiles in the ascent of alkaline magma with special reference to xenolith-bearing mafic lavas. Contrib. Mineral. Petrol. $88,217-232$.

Spera, F.J., 2000. Physical properties of magma. In: Sigurdsson, H. (Ed.), Encyclopedia of Volcanoes. Academic Press, New York, pp. 171-191.

Spera, F.J., Borgia, A., Strimple, J., Feigenson, M., 1988. Rheology of melts and magmatic suspensions. 1. Design and calibration of a concentric cylinder viscometer for application to rhyolitic magma. J. Geophys. Res. 93, 1027310294.

Spera, F.J., Stein, D.J., 2000. Comment on 'Rheology of bubble-bearing magmas' by Lejeune et al.. Earth Planet. Sci. Lett. $175,327-331$.
Stein, D.J., Spera, F.J., 1992. Rheology and microstructure of magmatic emulsions theory and experiments. J. Volcanol. Geotherm. Res. 49, 157-174.

Stein, D.J., Spera, F.J., 1993. Experimental rheometry of melts and supercooled liquids in the system $\mathrm{NaAlSiO}_{4}-\mathrm{SiO}_{2}$ : Implications for structure and dynamics. Am. Mineral. 78, 710-723.

Stein, D.J., Spera, F.J., 1998. New high-temperature rotational rheometer for silicate melts, magmatic suspensions and emulsions. Rev. Sci. Instrum. 69, 3396-3402.

Sura, V., Panda, P., 1990. Viscosity of porous glasses. J. Am. Ceram. Soc. 73, 2697-2701.

Taylor, G.I., 1932. The viscosity of a fluid containing small droplets of another fluid. Proc. R. Soc. London A 138, 4148.

Walker, D., Mullins, O., Jr., 1981. Surface tension of natural silicate melts from $1200^{\circ}-1500^{\circ} \mathrm{C}$ and implications for melt structure. Contrib. Mineral. Petrol. 76, 455-462.

Watson, E.B., 1994. Diffusion in volatile-bearing magmas. In: Carroll, M.R., Holloway, J.R. (Eds.), Volatiles in Magmas. Rev. Mineral. 30, 371-411.

Watson, E.B., Baker, D.R., 1991. Chemical diffusion in magmas: An overview of experimental results and geochemical applications. In: Perchuk, L.L., Kushiro, I. (Eds.), Physical Chemistry of Magmas. Springer-Verlag, New York, pp. 120 151.

Zarzycki, J., 1991. Glasses and the Vitreous State, transl. W.D. Scott and C. Massart. Cambridge University Press, New York, $505 \mathrm{pp}$.

Zhou, H., Pozrikidis, C., 1993. The flow of suspensions in channels: Single files of drops. Phys. Fluids A 5, 311-324. 